\title{
Neurosurgical Meningitis: Clinico-Microbiological Profile and Treatment Outcome from a Tertiary Care Center in India
}

\author{
Ravikant Porwal ${ }^{1}$ Abdul Ghafur ${ }^{1}$ Vidyalakshmi P. R. ${ }^{1} \quad$ Priyadarshini Kannaian $^{2}$ \\ Pradeepa Arivazhaghan ${ }^{2}$ \\ ${ }^{1}$ Department of Infectious Diseases, Apollo Hospitals, Chennai, India \\ ${ }^{2}$ Apollo Speciality Hospitals, Chennai, India \\ Address for correspondence Abdul Ghafur, MRCP, Department of \\ Infectious Diseases, Apollo Speciality Hospital, Padma Complex, 320 \\ Indian J Neurosurg 2015;4:2-7. \\ Anna Salai, Chennai 600035, India (e-mail: drghafur@hotmail.com).
}

\begin{abstract}
Background Meningitis following neurosurgical procedure is a well-recognized and potentially fatal complication. The Indian literature on microbiological epidemiology is scarce. The aim of our study was to know clinical, microbiological profile and treatment outcomes of patients with neurosurgical meningitis at our center.

Methods This was a retrospective observational cohort study of 25 culture-proven neurosurgical meningitis cases performed at the Apollo Speciality Hospital, Chennai, India, between January 2009 and May 2012.

Results In our study, nine patients had skull fracture and cerebrospinal fluid leak, nearly $50 \%$ of the patients underwent craniotomy, and five patients had endoscopic surgery while $64 \%$ of the patients required shunt placement or drains. Only nine patients (36\%) had definite clinical signs of meningitis and mean duration of onset of symptoms from surgery was 11.12 days. A total of 18 patients (72\%) had gramnegative bacterial meningitis and majority (83.3\%) was due to carbapenem-resistant organisms. Predominant isolate was Pseudomonas aeruginosa (44.4\%), and the second most common isolate was Acinetobacter baumannii (33.3\%). Among cases of gramnegative bacterial meningitis, patients who had carbapenem-resistant isolates were

Keywords

- neurosurgical meningitis

- multidrug-resistant gram-negative meningitis

- carbapenem-resistant meningitis given combination antimicrobials (carbapenem/cefepime tazobactam with colistin/ gentamicin) as per susceptibility via intravenous and intrathecal through the drain (extraventricular or lumbar). Only five patients (27.7\%) had a complete cure.

Conclusion Gram-negative organisms, mainly Pseudomonas and Acinetobacter, are predominant pathogen in neurosurgical meningitis in our center. While treating multidrug-resistant gram-negative meningitis, device removal and a combination of antimicrobial agents via both intravenous and intraventricular routes are crucial to achieve cure.
\end{abstract}

\section{Introduction}

Meningitis following neurosurgical procedure is a wellrecognized and potentially fatal complication. ${ }^{1,2}$ Knowledge of risk factors and local microbiological epidemiology is crucial for the successful treatment of these patients. ${ }^{3}$ Increasing prevalence of multidrugresistant organisms in health care settings makes it an even more difficult to treat entity. The Indian literature is scarce; however, a study from National Institute of Mental Health and Neurosciences (NIMHANS) showed gramnegative pathogens as a major causative agents. ${ }^{4}$ The aim of our study was to know clinical, microbiological profile and treatment outcomes of patients with neurosurgical meningitis at our center. published online March 20, 2015
DOI http://dx.doi.org/ $10.1055 / \mathrm{s}-0035-1549112$ ISSN 2277-954X. (c) 2015 Neurological Surgeons' Society of India
License terms

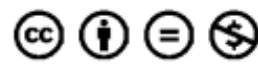




\section{Methods}

This was a retrospective observational cohort study performed at the Apollo Speciality Hospital, which is an oncology and neurosurgical center in Chennai, India, between January 2009 and May 2012.

A total of 588 cerebrospinal fluid (CSF) cultures were done during the same period, out of which 25 were culture positive (-Table 1). The Universal Hospital Identification Numbers of the culture-positive cases were tracked from the microbiology laboratory and then records were retrieved from the medical records department and were analyzed.

Patient characteristics such as age, demographics, sex, presence of comorbidities, Glasgow Coma Scale (GCS), presence of CSF rhinorrhea, fracture of skull base, prophylactic antibiotics, receipt of steroids, type of surgery, intraoperative antibiotics, presence of a device, clinical signs of meningitis, CSF picture with microbiological details, and treatment outcome were recorded (-Table 2 ).

Centers for Disease Control and Prevention's criteria were used to define nosocomial meningitis. ${ }^{5}$ Definitive meningitis was defined if the patients had the following: (1) new onset mental status change, (2) CSF cell count $>1,000$ cells with polymorph predominance, (3) CSF to serum glucose ratio $<0.4$, and (4) positive CSF culture for organism. Probable meningitis was diagnosed if the patients had the following: (1) new onset mental status change, (2) CSF cell count between 500 and 1,000 cells with mixed or polymorphic, (3) CSF to serum glucose ratio $<0.5$, and (4) positive CSF culture for organism.

Complete cure was defined by full clinical recovery and resolution of CSF pleocytosis with negative CSF culture at the end of treatment.

The identification and antibiotic susceptibility pattern of isolates were performed using microbroth dilution on VITEK 2 (bioMérieux, France) as per the Clinical and Laboratory Standards Institute guidelines. The minimum inhibitory concentration (MIC) for antibiotics, such as cefoperazonesulbactam and cefepime/tazobactam, are not elucidated in the current Clinical and Laboratory Standards Institute guidelines; hence, the breakpoint of cefoperazone and cefepime was applied for cefoperazone/sulbactam and cefepime/tazobactam, respectively. Antibiotic discs for these drugs were obtained from HiMedia Laboratory India. Colistin and vancomycin MICs were performed using the Etest strip (bioMérieux, France).

\section{Results}

During the study period, a total of 25 cases were diagnosed and treated for definitive or probable neurosurgical meningitis at our center. The median age of patients was 38 years with 18 (72\%) being male patients. Twelve patients (48\%) were admitted with traumatic head injury while rest had tumors and congenital anomalies. Only six patients had comorbid condition, that is, diabetes in four patients, coronary artery disease and hypertension in two patients, and one patient was human immunodeficiency virus positive.
All patients underwent neurosurgical intervention. Nine patients had skull fracture and CSF leak. Nearly 50\% of the patients underwent craniotomy, while 16 patients (64\%) required shunt placement or drain in situ. (Seven patients had a shunt; out of which, one was ventriculosubgaleal, one was thecoperitoneal, and five were ventriculoperitoneal shunts.) Drains which were either lumbar or external ventricular drainage (EVD) were present in nine patients. Endoscopic surgeries were performed in five patients, out of which four were elective procedures and one was an emergency procedure. Four out of the five procedures were CSF leak repair and one was an excision of the tumor. A total of 14 surgeries (56\%) were emergent in nature. Two patients were operated at the other facility and were shifted for further care to our center and were later diagnosed to have meningitis at our hospital. The median time of hospitalization was 37 days with a mean of 11.36 days of intensive care unit stay. All these patients received perioperative antibiotics for a mean duration of 3.24 days which mainly included third-generation cephalosporin and aminoglycosides. Only nine patients (36\%) had classical clinical signs of meningitis, and mean duration of onset of symptoms from surgery was 11.12 days. CSF analysis was performed with a mean of 3 days after the symptom onset.

Out of 25 cases, 16 (64\%) cases met the definitive diagnostic criteria while remaining 9 cases were diagnosed as probable meningitis.

Overall, 18 patients (72\%) had gram-negative bacterial meningitis and 15 out of these (83.3\%) were due to carbapenem-resistant organisms. Predominant isolate was Pseudomonas aeruginosa (44.4\%), the second most common was Acinetobacter baumannii (33.3\%), and Enterobacteriaceae was isolated in $16.6 \%$ of these cases. Gram-positive organisms were isolated in seven cases (28\%) and among them Staphylococcus epidermidis and Staphylococcus aureus were in five cases, both were methicillin susceptible while Streptococcus pneumoniae and Enterococci were found in one patient each.

Among the cases of gram-positive meningitis, patients who had S. epidermidis and S. aureus (methicillin-sensitive $S$. epidermidis and methicillin-sensitive $S$. aureus) were successfully treated with first-generation cephalosporin intravenously for 2 weeks. Methicillin-sensitive S. aureus meningitis patient required shunt removal which was done a few days after the diagnosis of meningitis. Enterococcal meningitis patient was given vancomycin intravenously but died on the 10 th day.

Among cases of gram-negative bacterial meningitis (-Table 3), patients who had carbapenem-resistant isolates were given 3 weeks of combination therapy (meropenem or cefepime-tazobactam as per susceptibility plus colistin) intravenously along with 5 to 7 days of intrathecal colistin or gentamicin as per susceptibility through drain (extraventricular or lumbar). Nine patients received intrathecal or intraventricular antibiotics. The drugs that were used for therapy via this route were colistin, polymyxin $\mathrm{B}$, amikacin, and vancomycin. If the patient had organisms that were carbapenem resistant particularly Pseudomonas and Acinetobacter, this route was 


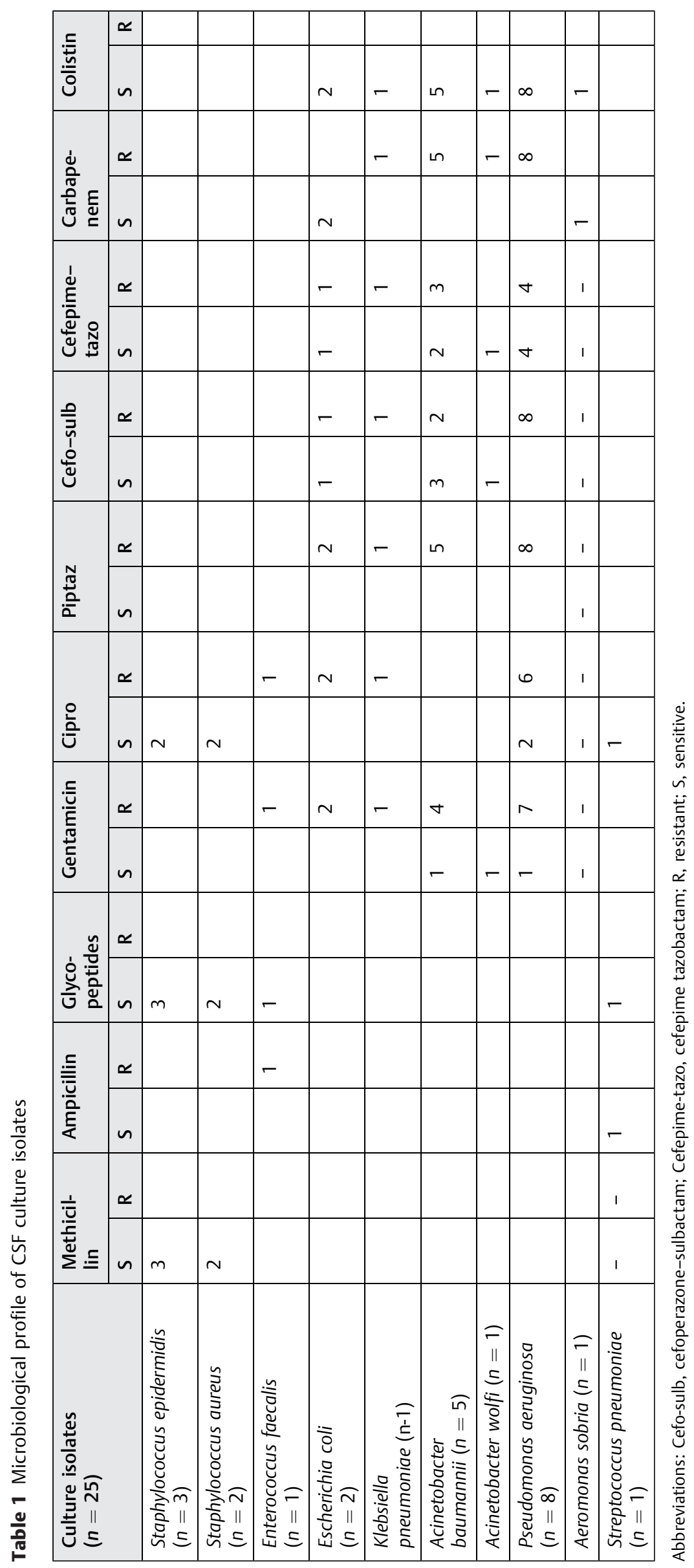


Table 2 Demographics and clinical characteristics

\begin{tabular}{|c|c|}
\hline Characteristics & Value \\
\hline Age (median), y & 38 \\
\hline \multicolumn{2}{|l|}{$\operatorname{Sex}(n)$} \\
\hline Male & 18 \\
\hline Female & 7 \\
\hline \multicolumn{2}{|l|}{ Primary diagnoses $(n)$} \\
\hline Traumatic head injury & 12 \\
\hline Tumor & 9 \\
\hline Congenital anomaly & 4 \\
\hline \multicolumn{2}{|l|}{ Comorbidity $(n)$} \\
\hline Diabetes mellitus & 4 \\
\hline HIV & 1 \\
\hline Days of hospitalization (median) & 37 \\
\hline ICU days (mean) & 11.36 \\
\hline Apache score (mean) & 16.92 \\
\hline \multicolumn{2}{|l|}{ Clinical parameters (no. of patients) } \\
\hline Fever $\left(>101^{\circ} \mathrm{F}\right)$ & 13 \\
\hline Altered sensorium (new onset) & 5 \\
\hline Stiff neck & 5 \\
\hline CSF leak & 7 \\
\hline Skull fracture & 9 \\
\hline Antibiotic prophylaxis in days (mean) & 3.24 \\
\hline \multicolumn{2}{|l|}{ Surgical procedure } \\
\hline Endoscopic repair & 5 \\
\hline Craniotomy & 12 \\
\hline Laminectomy & 1 \\
\hline Shunt placement & 11 \\
\hline \multicolumn{2}{|l|}{ Nature of surgery } \\
\hline Emergency & 14 \\
\hline Elective & 9 \\
\hline Surgery at other facility & 2 \\
\hline Drain in situ for $>7 \mathrm{~d}$ (lumbar/EVD) & 16 cases \\
\hline $\begin{array}{l}\text { Postoperative days at } \\
\text { onset of symptoms (mean) }\end{array}$ & 11.12 \\
\hline $\begin{array}{l}\text { Days from symptom } \\
\text { onset to CSF analysis } \\
\text { (average no. of days from } \\
\text { symptom to CSF analysis) }\end{array}$ & $3 d$ \\
\hline \multicolumn{2}{|l|}{ CSF analysis } \\
\hline Definite meningitis & 16 \\
\hline Probable meningitis & 9 \\
\hline $\begin{array}{l}\text { Same culture isolates from non-CSF site } \\
\text { Three patients had bacteremia with the } \\
\text { same organisms. Three patients who grew } \\
\text { the organism in the CSF had colonization of } \\
\text { the respiratory tract. Patients grew the } \\
\text { same organism from the wound swab. }\end{array}$ & 10 patients \\
\hline
\end{tabular}

Abbreviations: CSF, cerebrospinal fluid; EVD, external ventricular drainage. chosen as intravenous colistin does not penetrate well into the CSF. Colistin does not penetrate the CSF well. Hence, carbapenems (although showed in vitro resistance on the isolates) were added to intravenous colistin for synergy. Out of these, 14 patients (77.7\%) required device removal. Removal of the device was suggested in all the cases if meningitis was due to an extensively drug-resistant organism or $S$. aureus, as these can form biofilms. However, if the patient improved on therapy with microbiological clearance of CSF, the device was retained at the discretion of the surgical team. Five patients (27.7\%) were cured completely and two patients died, while others had residual neurological deficit and partial resolution. Some patients were said to have partial resolution because these patients had microbiological cure and resolution of clinical symptoms; however, they did not have adequate improvement in GCS, and we were not sure how much of this was contributed by the meningitis. A single patient with Aeromonas sobria was treated with 2 weeks of intravenous meropenem and recovered fully.

\section{Discussion}

Meningitis is a well-known and fatal complication following head trauma and neurosurgical procedures. In our study, we found gram-negative organisms (72\%) as a major pathogen causing neurosurgical meningitis similar to a study in NIMHANS by Srinivas et al. Previous studies have also showed this finding as emerging pathogens in nosocomial meningitis. ${ }^{6}$ Prior use of third-generation cephalosporins was identified as common feature of patients with gram-negative meningitis in one study. ${ }^{7}$ Even in western studies though $S$. aureus is an important pathogen in postsurgical meningitis, gram-negative meningitis is emerging as major syndrome due to increased colonization in hospitalized patients. ${ }^{8}$

In our study, 9 patients had skull fracture and CSF leak, 16 patients had prolonged ( $>7$ days) duration of extraventricular drain or lumbar drain, and 5 had sinus approach surgical procedure, making these possible risk factors for developing neurosurgical meningitis. EVD provides a potential portal of entry for microorganisms and associated with a risk of infection of 4 to $11 \%$ for ventriculostomies and $4.2 \%$ for lumbar drains. ${ }^{9}$ As observed in our study, these factors have been reported as established risk factor for nosocomial meningitis in literature. ${ }^{10}$ The mean time to develop meningitis postneurosurgery was 11.12 days in our study. Three out of 25 patients were readmitted with clinical symptoms which is in concordance with the observation in literature. ${ }^{11}$ As reported in previous studies, the typical symptoms and signs were noted only in $36 \%$ of the patients in our study, suggesting that high index of clinical suspicion in the light of risk factors is crucial for early diagnosis. $^{12}$

In our study, predominant gram-negative isolates were $P$. aeruginosa and $A$. baumannii (77.7\%), and all were resistant to carbapenems but susceptible to colistin. Patients with these bacteria were treated with combination of antimicrobial agents administered via both intravenous 
6 Neurosurgical Meningitis: A Case Series Porwal et al.

Table 3 Treatment and outcome of various organisms

\begin{tabular}{|c|c|c|c|c|c|}
\hline \multirow{2}{*}{$\begin{array}{l}\text { Causative organ- } \\
\text { ism }\end{array}$} & \multicolumn{2}{|l|}{ Treatment } & \multicolumn{3}{|l|}{ Outcome } \\
\hline & Intravenous & Intrathecal & Device removal & $\begin{array}{l}\text { Complete } \\
\text { resolution }\end{array}$ & Died \\
\hline $\begin{array}{l}\text { Methicillin-sensitive } \\
\text { Staphylococcus } \\
\text { epidermidis }\end{array}$ & $\begin{array}{l}\text { Cefoperazone- } \\
\text { sulbactam-2 d, then } \\
\text { cefazolin-12 d }\end{array}$ & No & - & Yes & \\
\hline $\begin{array}{l}\text { Methicillin-sensitive } \\
\text { Staphylococcus } \\
\text { aureus }\end{array}$ & $\begin{array}{l}\text { Vancomycin-2 d, then } \\
\text { cloxacillin-12 d }\end{array}$ & No & $\begin{array}{l}\text { Shunt removal } \\
\text { performed }\end{array}$ & Yes & \\
\hline E. faecalis & Vancomycin-10 d & No & - & - & Yes \\
\hline $\begin{array}{l}\text { Streptococcus } \\
\text { pneumoniae }\end{array}$ & Ceftriaxone-14 d & & - & Yes & \\
\hline $\begin{array}{l}\text { Carbapenem- } \\
\text { resistant gram- } \\
\text { negative bacteria } \\
\text { (carbapenem- } \\
\text { resistant } \\
\text { Enterobacteriaceae, } \\
\text { Pseudomonas, } \\
\text { Acinetobacter } \\
\text { baumannii) }\end{array}$ & $\begin{array}{l}\text { Meropenem/cefepime, } \\
\text { tazobactum + colistin } \\
\text { for } 3 \mathrm{wk}\end{array}$ & $\begin{array}{l}\text { Gentamicin/colistin } \\
\text { for variable period. } \\
\text { (range } 5-7 \text { d). }\end{array}$ & $\begin{array}{l}14 \text { cases }(77.7 \%) \\
\text { required device } \\
\text { removal with } \\
\text { incomplete cure }^{\text {a }}\end{array}$ & 5 cases $(27.7 \%)$ & 2 patients \\
\hline $\begin{array}{l}\text { Extended spectrum } \\
\text { beta-lactamase- } \\
\text { producing } \\
\text { Enterobacteriaceae }\end{array}$ & Meropenem-3 wk & $\begin{array}{l}\text { Gentamicin/ } \\
\text { amikacin if } \\
\text { susceptible for 5-7 } \\
\text { d }\end{array}$ & - & Yes & \\
\hline Aeromonas sobria & Meropenem-2 wk & & - & Yes & \\
\hline
\end{tabular}

ancomplete cure: Patients who did not meet the criteria for complete cure or had persistent neurodeficit.

and intrathecal routes. Only $27.7 \%$ of these patients achieved complete clinical cure; two patients (11.11\%) died; and others developed visible morbidity, organ failures, and partial resolution despite therapy. These findings were different from published literature of very high mortality in such patients. ${ }^{13-15}$ Possible explanation to the better outcome in our patients could be the aggressive intraventricular and intrathecal therapy with device removal as needed. This could also be due to a bias in the calculation of mortality data, as we did not include those patients who had partial response initially and later on developed next episode of central nervous system (CNS) or non-CNS infection and remain morbid or expired later on. A study from NIMHANS by Srinivas et al also showed a low mortality similar to our study.

In our study, gram-positive bacterial meningitis represented nearly a quarter of cases with $85 \%$ clinical cure achieved with intravenous therapy alone. The limitation of our study was its retrospective design and unavailability of attributable mortality to various risk factors.

\section{Conclusion}

Early recognition and adequate treatment of neurosurgical meningitis, especially caused by multidrug-resistant gramnegative bacteria, is a serious challenge to the treating clinician.
CSF leak, skull fracture, prolonged placement of drains, and sinus approach in surgery are important risk factors in developing neurosurgical meningitis.

Gram-negative organisms, mainly Pseudomonas and Acinetobacter, are predominant pathogen in neurosurgical meningitis in our center.

Carbapenem resistance in both these pathogens is very high and poses significant therapeutic problems in cure. While treating patients with multidrug-resistant gramnegative meningitis, device removal, combination of antimicrobial agents, and administration via both intravenous and intraventricular routes are crucial to achieve cure.

Conflict of Interest

None.

Notes

We did not get any support in the form of grants, equipment, drugs, or all of these. This article has not been presented anywhere else. All the authors have contributed in data collection, analysis, and article writing this article. This article has been read and approved by all the authors and represent honest work. 


\section{Acknowledgment}

None.

\section{References}

1 Korinek AM, Baugnon T, Golmard JL, van Effenterre R, Coriat P, Puybasset L. Risk factors for adult nosocomial meningitis after craniotomy: role of antibiotic prophylaxis. Neurosurgery 2006; 59(1):126-133, discussion 126-133

2 McClelland S III, Hall WA. Postoperative central nervous system infection: incidence and associated factors in 2111 neurosurgical procedures. Clin Infect Dis 2007;45(1):55-59

3 Tunkel AR, Hartman BJ, Kaplan SL, et al. Practice guidelines for the management of bacterial meningitis. Clin Infect Dis 2004;39(9): 1267-1284

4 Srinivas D, Veena Kumari HB, Somanna S, Bhagavatula I, Anandappa $C B$. The incidence of postoperative meningitis in neurosurgery: an institutional experience. Neurol India 2011; 59(2):195-198

5 Garner JS, Jarvis WR, Emori TG, Horan TC, Hughes JM. CDC definitions for nosocomial infections, 1988. Am J Infect Control 1988;16(3):128-140

6 Metan G, Alp E, Aygen B, Sumerkan B. Carbapenem-resistant Acinetobacter baumannii: an emerging threat for patients with post-neurosurgical meningitis. Int J Antimicrob Agents 2007; 29(1):112-113

7 Sacar S, Turgut H, Toprak S, et al. A retrospective study of central nervous system shunt infections diagnosed in a university hospital during a 4-year period. BMC Infect Dis 2006;6:43
8 Nguyen MH, Harris SP, Muder RR, Pasculle AW. Antibioticresistant Acinetobacter meningitis in neurosurgical patients. Neurosurgery 1994;35(5):851-855, discussion 855

9 O'Neill E, Humphreys H, Phillips J, Smyth EG. Third-generation cephalosporin resistance among Gram-negative bacilli causing meningitis in neurosurgical patients: significant challenges in ensuring effective antibiotic therapy. J Antimicrob Chemother 2006;57(2):356-359

10 Mayhall CG, Archer NH, Lamb VA, et al. Ventriculostomy-related infections. A prospective epidemiologic study. N Engl J Med 1984;310(9):553-559

11 Kourbeti IS, Jacobs AV, Koslow M, Karabetsos D, Holzman RS. Risk factors associated with postcraniotomy meningitis. Neurosurgery 2007;60(2):317-325, discussion 325-326

12 Siegman-Igra Y, Bar-Yosef S, Gorea A, Avram J. Nosocomial acinetobacter meningitis secondary to invasive procedures: report of 25 cases and review. Clin Infect Dis 1993;17(5): 843-849

13 Weisfelt M, van de Beek D, Spanjaard L, de Gans J. Nosocomial bacterial meningitis in adults: a prospective series of 50 cases. J Hosp Infect 2007;66(1):71-78

14 Metan G, Alp E, Aygen B, Sumerkan B. Acinetobacter baumannii meningitis in post-neurosurgical patients: clinical outcome and impact of carbapenem resistance. J Antimicrob Chemother 2007; 60(1):197-199

15 Huang CR, Lu CH, Chuang YC, et al. Adult Pseudomonas aeruginosa meningitis: high incidence of underlying medical and/or postneurosurgical conditions and high mortality rate. Jpn J Infect Dis 2007;60(6):397-399 